\title{
Fecal microbiota transplantation associated with 10 years of stability in a patient with SPMS
}

Seraj Makkawi, MBBS, FRCPC, ABPN, MSCS, CRND, Carlos Camara-Lemarroy, MD, and Luanne Metz, MD, FRCPC

Neurol Neuroimmunol Neuroinflamm 2018;5:e459. doi:10.1212/NXI.0000000000000459

Several studies link the gut microbiome and MS immunopathogenesis. Fecal microbiota transplantation (FMT), the process of transferring fecal microbiota from a healthy donor to a patient, successfully treats recurrent Clostridium difficile enterocolitis and may benefit autoimmune diseases. The potential short-term efficacy of this procedure has been reported in MS. Here, we describe a patient with secondary progressive MS (SPMS) who achieved disease stability for over 10 years following FMT.

\section{Case report}

A 61-year-old woman with MS was followed up in the Calgary MS Clinic since 1988 (age 33 years). She had 7 relapses between 1998 and 2001, and her MRI showed numerous periventricular, juxtacortical, brainstem, and corpus callosum lesions confirming relapsing remitting MS (RRMS). CSF was not obtained. She started glatiramer acetate in 2001 and has remained on it since. She has been relapse-free and had stable brain MRI (no new lesions) since. However, between 2001 and 2005, her balance, ambulation, lower limb power, bladder function, and fatigue gradually worsened. Her Expanded Disability Status Scale (EDSS) increased from 2.0 to 3.0. Because of progressive symptom worsening, and stable MRI, this suggested a diagnosis of SPMS. During 2005 and 2006, she had several bouts of $C$ difficile enterocolitis following clindamycin treatment of a gingival infection. Her EDSS score increased to 6.0. As she was resistant to multiple courses of metronidazole and vancomycin, she received a single FMT in 2006 from her partner via rectal enema using a standard protocol. ${ }^{1}$ Her EDSS score immediately stabilized without other treatment or lifestyle changes. Over the next 10 years, her Functional System scores minimally improved, as did Modified Multiple Sclerosis Functional Composite scores after 2012 when this measure was routine in our clinic (figure).

\section{Discussion}

The gut microbiome consists of billions of bacteria, fungi, and viruses, which participate in maintaining gut homeostasis. Recently, there has been explosion of interest in the gut microbiota and their impact on normal host immune function and in the development of autoimmune diseases such as MS.

Evidence suggesting a role for the gut microbiome in MS originated from preclinical investigations using the murine model of experimental autoimmune encephalomyelitis (EAE). ${ }^{2}$ Mice bred under germ-free conditions are resistant to EAE induction, and after induction, they have fewer activated pathogenic lymphocytes and increased T-regulatory cells. These changes, and resistance to EAE, can be reversed after recolonization with fecal microbiota from mice
Correspondence

Dr. Makkawi

smakkawi@hotmail.com 

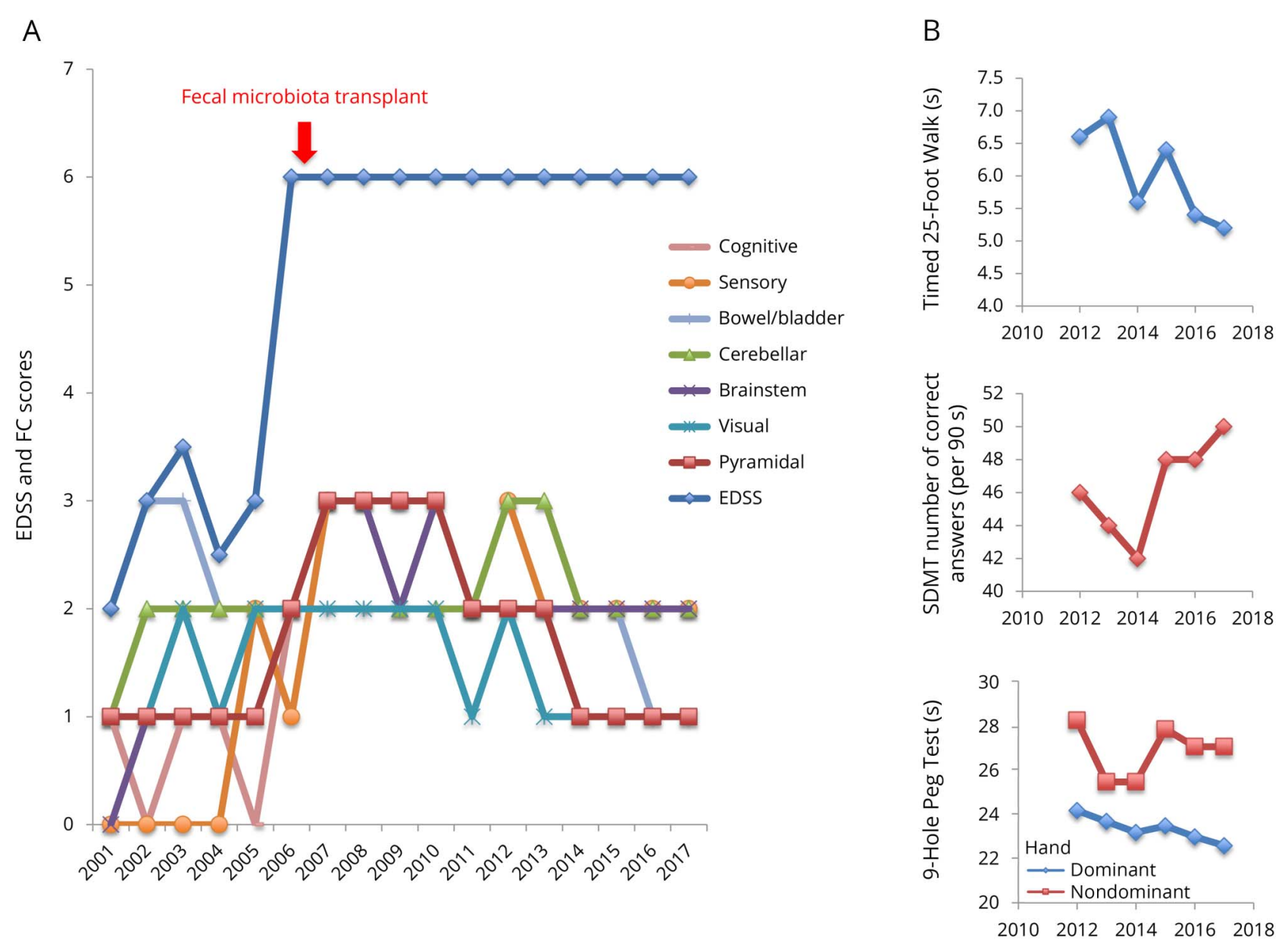

(A) EDSS and FS scores. (B) Modified MSFC scores. All scores were recorded in the patient chart at the time of each visit. The first clinic visit after fecal microbiota transplantation was in 2007. Oral SDMT replaces the PASAT. EDSS = Expanded Disability Status Scale; FS = Functional System; MSFC = Multiple Sclerosis functional composite; SDMT = Symbol Digit Modalities Test; PASAT = Paced Auditory Serial Addition Test.

bred under standard conditions. Together, this evidence builds a case for the gut microbiome as a neuroimmune modulator in EAE. ${ }^{3}$

Recent studies have shown that gut microbiome compositions in patients with RRMS differ from those in controls. Some differences have been associated with relapse risk and peripheral immunologic derangements. ${ }^{4}$ However, a clear and consistent "MS microbiome phenotype" has not been described, and a myriad of different species have been implicated.

The potential role of the gut microbiome in MS pathogenesis has led to proposals for microbiome modification as a therapeutic strategy. Although dietary interventions and the use of probiotics have not been effective, FMT presents an ideal method of microbiome modification. Decades of safe use make it an attractive treatment option for autoimmune diseases, including MS. ${ }^{5}$

In a previous report, three people with MS had significant neurologic symptom improvement after FMT for constipation. ${ }^{6}$
To the best of our knowledge, this case is the first report suggesting the potential long-term benefit of FMT on MS disease progression. An inflammatory response, triggered by recurrent $C$ difficile infections, likely led to rapid neurologic worsening in 2006 that stabilized after correction of gut dysbiosis by FMT. Her symptoms increased gradually, although her EDSS did not increase continuously before 2006, so it is possible that she did not have SPMS. Her neurologic deficits may have been more amenable to reversal than would be expected if they had been longstanding. We hypothesize that her transplanted gut microbiome failed to drive progression and possibly permitting limited endogenous repair. However, as we do not know the composition of her microbiome before she acquired $C$ difficile, or after the FMT, this remains speculative. As no interventions have yet been shown to stimulate repair, the time course of recovery in MS remains unknown. Control of ongoing inflammation is, however, believed to be important.

The prospect of a novel treatment of MS based on a sound theoretical basis is encouraging. Clinical trials are required to 
guide the future use of FMT by evaluating its effectiveness, safety profile, and mechanism of action. Indeed, a phase- 2 trial is ongoing. ${ }^{7}$ Challenges will include donor and patient selection, dosing, and selection of outcomes.

\section{Author contributions}

S.M. and C.C.-L. prepared the initial draft of the manuscript. S.M., C.C.-L., and L.M. contributed to the revision of the manuscript. S.M., C.C.-L., and L.M. agreed to the publication of this version of the manuscript.

\section{Study funding}

No targeted funding reported.

\section{Disclosure}

S. Makkawi and C. Camara-Lemarroy report no disclosures. L. Metz served on the scientific advisory board of DSMB and Rick Hansen Institute; has a patent pending for Combination of minocycline plus hydroxychloroquine in demyelinating disease; consulted for EMD Serono; and received research support from the Multiple Sclerosis Society of Canada. Full disclosure form information provided by the authors is available with the full text of this article at Neurology.org/NN.

Received January 3, 2018. Accepted in final form February 28, 2018.

\section{References}

1. Louie T, Adams PC. Nature's therapy for recurrent Clostridium difficile diarrhea. Can J Gastroenterol Hepatol 2008;22:455-456.

2. Berer $\mathrm{K}$, Mues $\mathrm{M}$, Koutrolos $\mathrm{M}$, et al. Commensal microbiota and myelin autoantigen cooperate to trigger autoimmune demyelination. Nature 2011;479:538-541.

3. Adamczyk-Sowa M, Medrek A, Madej P, Michlicka W, Dobrakowski P. Does the gut microbiota influence immunity and inflammation in multiple sclerosis pathophysiology? J Immunol Res 2017;2017:7904821.

4. Pröbstel AK, Baranzini SE. The role of the gut microbiome in multiple sclerosis risk and progression: towards characterization of the "MS microbiome". Neurotherapeutics 2018;15:126-134.

5. $\mathrm{Xu} \mathrm{MQ}$, Cao HL, Wang WQ, et al. Fecal microbiota transplantation broadening its application beyond intestinal disorders. World J Gastroenterol 2015;21:102-111.

6. Borody TJ, Leis SM, Campbell J, Torres M, Nowak A. Fecal microbiota transplantation (FMT) in multiple sclerosis (MS) [abstract]. Am J Gastroenterol 2011; 106:S352.

7. Kremenchutzky M. Fecal microbial transplantation in relapsing multiple sclerosis patients. In: ClinicalTrials.gov [online]. Available at: clinicaltrials.gov/ct2/show/ NCT03183869. Accessed February 2, 2018 


\section{Neurology \\ Neuroimmunology \& Neuroinflammation}

\section{Fecal microbiota transplantation associated with 10 years of stability in a patient with SPMS}

Seraj Makkawi, Carlos Camara-Lemarroy and Luanne Metz

Neurol Neuroimmunol Neuroinflamm 2018;5;

DOI 10.1212/NXI.0000000000000459

This information is current as of April 3, 2018

Updated Information \&

Services

References

Subspecialty Collections

Permissions \& Licensing

Reprints including high resolution figures, can be found at:

http://nn.neurology.org/content/5/4/e459.full.html

This article cites 6 articles, 0 of which you can access for free at: http://nn.neurology.org/content/5/4/e459.full.html\#\#ref-list-1

This article, along with others on similar topics, appears in the following collection(s):

All Demyelinating disease (CNS)

http://nn.neurology.org//cgi/collection/all_demyelinating_disease_cns Multiple sclerosis

http://nn.neurology.org//cgi/collection/multiple_sclerosis

Information about reproducing this article in parts (figures,tables) or in its entirety can be found online at:

http://nn.neurology.org/misc/about.xhtml\#permissions

Information about ordering reprints can be found online: http://nn.neurology.org/misc/addir.xhtml\#reprintsus

Neurol Neuroimmunol Neuroinflamm is an official journal of the American Academy of Neurology.

Published since April 2014, it is an open-access, online-only, continuous publication journal. Copyright

Copyright (C) 2018 The Author(s). Published by Wolters Kluwer Health, Inc. on behalf of the American

Academy of Neurology.. All rights reserved. Online ISSN: 2332-7812.

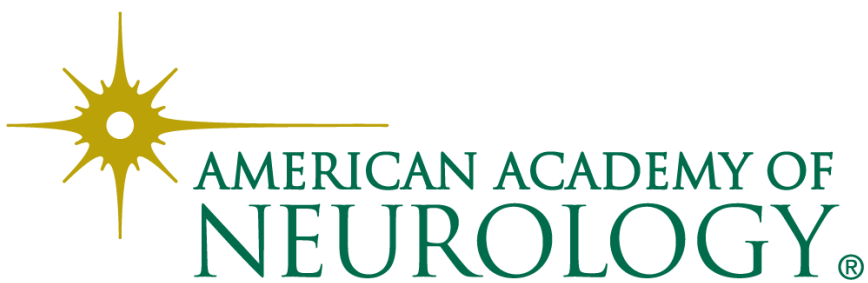

